\title{
Iron Sequestration by Macrophages Decreases the Potential for Extracellular Hydroxyl Radical Formation
}

\author{
Oyebode Olakanmi, ${ }^{*}$ Stephen E. McGowan, ${ }^{\star *}$ Michael B. Hayek, ${ }^{\star}$ and Bradley E. Britigan * \\ ${ }^{*}$ Departments of Internal Medicine and Research Service, VA Medical Center and ${ }^{\ddagger}$ Department \\ of Internal Medicine, University of Iowa College of Medicine, Iowa City, IA 52242
}

\begin{abstract}
Alveolar macrophages (AM) from smokers contain a much higher quantity of intracellular iron than AM from nonsmokers. Since some forms of iron will catalyze the formation of hydroxyl radical $(\cdot \mathrm{OH})$ from superoxide and hydrogen peroxide, the ability of AM derived from smokers and nonsmokers to generate $\cdot \mathrm{OH}$ was assessed. No detectable $\cdot \mathrm{OH}$ was produced by $A M$ from either source, suggesting that iron sequestration by AM may limit the potential for $\cdot \mathrm{OH}$-mediated lung injury. Consistent with this hypothesis, the ability of bronchoalveolar lavage fluid (BAL) from smokers and nonsmokers to act as an - OH catalyst decreased after exposure to AM. We found that, like AM, human monocyte-derived macrophages (MDM) have the ability to acquire large quantities of iron from small low molecular weight iron chelates as well as decrease the ability of BAL to act as a $\cdot$ OH catalyst. When MDM or AM were exposed to the iron chelates or BAL they were then able to generate $\cdot \mathrm{OH}$ after phorbol myristate acetate stimulation. However, when acutely iron-loaded or BAL-exposed MDM were placed in culture, their ability to produce $\cdot$ OH decreased with time to the level of non-iron-exposed controls. This process correlated with iron translocation from the plasma membrane to the cytosol as well as a 3-9-fold increase in cellular ferritin. No increase in antioxidant enzyme levels or induction of the heat shock response was observed. Iron sequestration by macrophages may protect nearby cells from exposure to potentially cytotoxic iron-catalyzed oxidants such as $\cdot$ OH. (J. Clin. Invest. 1993. 91:889-899.) Key words: superoxide • ferritin • free radical $\cdot$ cigarette
\end{abstract}

\section{Introduction}

Cigarette consumption has long been associated with chronic pulmonary diseases such as emphysema and chronic bronchitis (1). The airways of smokers contain an increased number of macrophages (2) and, although not uniformly observed, several studies suggest these macrophages have increased metabolic activity (3-6). Alveolar macrophages (AM) ${ }^{1}$ from

Address correspondence to Bradley E. Britigan, M.D., Department of Internal Medicine, University of Iowa, SW54 GH, Iowa City, IA 52242. 1992

Received for publication 1 July 1991 and in revised form 14 October

1. Abbreviations used in this paper: AM, alveolar macrophages; BAL, bronchoalveolar lavage; DMPO, 5,5 dimethyl-1-pyrroline- $N$-oxide; DTPA, diethylenetriaminepentaacetic; EPR, electron paramagnetic resonance spectrometry; FeNTA, ferric nitrilotriacetic acid; MDM, monocyte-derived macrophages; $\cdot \mathrm{OH}$, hydroxyl radical; $\mathrm{PBN}, N$-t-butyl- $\alpha$-phenyl-nitrone; 4-POBN, $\alpha$-(4-pyridyl-1-oxide)- $N$-t-butyl- $\alpha$ phenyl-nitrone; TBA, thiobarbituric acid.

The Journal of Clinical Investigation, Inc.

Volume 91, March 1993, 889-899 smokers contain increased amounts of iron relative to nonsmokers (7-9) and it has recently been shown that this iron is stored within the macrophage both as ferritin and as insoluble iron complexes, most likely hemosiderin (8). Other disease states (e.g., secondary hemochromatosis) are also associated with increased iron content of some tissue macrophages $(10,11)$.

Like other phagocytes, the optimal function of AM and other tissue macrophages is linked to their capacity to reduce molecular oxygen to superoxide $\left(\cdot \mathrm{O}_{2}^{-}\right)$and hydrogen peroxide $\left(\mathrm{H}_{2} \mathrm{O}_{2}\right)$. It has been suggested that lung injury in a variety of conditions, including that associated with cigarette smoking, could relate in part to damage to pulmonary tissue from phagocyte-derived oxidants (12). Similarly, other tissues are susceptible to such injury (13).

Superoxide and $\mathrm{H}_{2} \mathrm{O}_{2}$, the initial products of macrophage oxygen reduction (14), are only moderately reactive oxidants. In vitro, in the presence of a transition metal catalyst such as iron, $\mathrm{H}_{2} \mathrm{O}_{2}$ and $\cdot \mathrm{O}_{2}^{-}$react to form hydroxyl radical $(\cdot \mathrm{OH})$ via the Haber-Weiss reaction (15). Hydroxyl radical is an extremely reactive oxidant whose formation has been implicated in some forms of phagocyte-associated tissue injury (13).

Given the increased iron content of AM from smokers, it seemed possible that increased formation of $\cdot \mathrm{OH}$, through the interaction of this iron with macrophage-derived $\cdot \mathrm{O}_{2}^{-} / \mathrm{H}_{2} \mathrm{O}_{2}$, could play a role in cigarette-associated lung injury. Similarly, - $\mathrm{OH}$ generated by other iron-overloaded macrophages could contribute to the pathogenesis of conditions such as secondary hemochromatosis. However, $\cdot \mathrm{O}_{2}^{-}$and $\mathrm{H}_{2} \mathrm{O}_{2}$ generated by stimulated macrophages are secreted extracellularly and the presence of intracellular antioxidant systems (e.g., SOD and catalase) would markedly decrease the likelihood of significant interaction between $\cdot \mathrm{O}_{2}^{-} / \mathrm{H}_{2} \mathrm{O}_{2}$ and macrophage iron stores. Consequently, it seemed equally plausible that intracellular sequestration of iron by macrophages may serve to limit the potential for extracellular $\cdot \mathrm{OH}$ generation, thereby protecting surrounding cells from potential oxidant-mediated injury. To examine these two possibilities, we assessed the potential for - OH generation by human AM obtained by bronchoalveolar lavage (BAL) from healthy smokers and nonsmokers, as well as by human monocyte-derived macrophages (MDM) from healthy individuals treated in vitro in such a way as to increase their iron content.

\section{Methods}

Alveolar macrophages. AM were obtained by BAL of two pulmonary subsegments using a total of $250 \mathrm{ml}$ of $150 \mathrm{mM} \mathrm{NaCl}$ as previously reported (7). Cells were concentrated from BAL by centrifugation at $300 \mathrm{~g}$ for $10 \mathrm{~min}$, the cells were washed, resuspended in RPMI 1640 media containing $20 \mathrm{mM}$ Hepes, $100 \mathrm{U} / \mathrm{ml}$ of penicillin, and 100 $\mu \mathrm{g} / \mathrm{ml}$ streptomycin (University of Iowa Cancer Center, Iowa City, IA), and differential cell counts were obtained. Any contaminating 
erythrocytes were lysed with $150 \mathrm{mM} \mathrm{NH}_{4} \mathrm{Cl}$ containing $10 \mathrm{mM}$ Tris, $\mathrm{pH}$ 7.4. AM were washed with PBS three times and finally suspended in HBSS without phenol red (HBSS, University of Iowa Cancer Center). For nonsmokers, BAL yielded $3.7 \pm 1.8 \times 10^{7}$ cells (mean \pm SEM) of which $93.8 \pm 6.8 \%$ were AM $(n=4)$. For smokers, BAL resulted in $12.9 \pm 5.8 \times 10^{7}$ cells $($ mean \pm SEM) of which $97.1 \pm 1.7 \%$ were AM $(n$ $=8$ ). In some experiments, BAL fluid from which cells had been removed by centrifugation and filtration was employed. Similar results were obtained regardless of whether these samples were studied on the day of acquisition or frozen at $-70^{\circ} \mathrm{C}$ until needed.

MDM. Human MDM were obtained as previously described (16). Briefly, mononuclear cells, separated from heparinized venous blood after dextran sedimentation and centrifugation through Ficoll-Hypaque, were placed in sterile petri dishes. Nonadherent cells were removed by washing and the resulting adherent cells maintained in culture for up to $10 \mathrm{~d}$ using MEM- $\alpha$ (University of Iowa Cancer Center) supplemented with $13 \%$ autologous plasma, penicillin $(100 \mathrm{U} / \mathrm{ml})$, and streptomycin $(100 \mu \mathrm{g} / \mathrm{ml})$. Before study, the petri dishes were chilled on crushed ice and MDM were released from the plate into suspension by gentle scraping.

To obtain iron-overloaded MDM, mononuclear phagocytes prepared as above were washed twice with MEM- $\alpha$ and incubated for 30 min at $37^{\circ} \mathrm{C}$ in either BAL fluid or MEM- $\alpha$ containing $0.5 \mathrm{mM}$ ferric nitrilotriacetic acid (FeNTA), ferric adenosine 5'-diphosphate (FeADP), or ferric citrate (Fe-citrate), prepared by the mixture of equimolar amounts of $\mathrm{FeCl}_{3}$ and the desired chelate. Cells were then washed three times with MEM- $\alpha$ to remove non-cell-associated iron. These cells are referred to as acutely iron-loaded MDM.

In some experiments the mononuclear phagocytes were incubated in the presence of BAL, FeNTA, FeADP, or Fe-citrate as above, washed, and then placed back in culture (MEM- $\alpha$ ) for up to an additional $5 \mathrm{~d}$. These cells are referred to as chronic iron-loaded MDM. Similar results were obtained regardless of whether the cells were loaded with iron as monocytes or as MDM.

Deoxyribose oxidation assay. Hydroxyl radical-mediated oxidation of 2-deoxyribose to form thiobarbituric acid (TBA)-reactive oxidation products was measured using a slight modification of previously described procedures (17-19). AM (5-7.5 $\left.\times 10^{6} / \mathrm{ml}\right)$ or MDM (2-5 $\times 10^{6} / \mathrm{ml}$ ) were suspended in PBS containing $0.05 \%$ glucose (PBS-glucose) and 2-deoxyribose ( $5 \mathrm{mM}$; Sigma Chemical Co., St. Louis, MO). After addition of the desired stimulant, the suspension was incubated for 40 to $60 \mathrm{~min}$ at $37^{\circ} \mathrm{C}$. The reaction was then terminated by the addition of 6\% TCA, after which 1\% TBA (Sigma Chemical Co.) was added and the mixture was boiled for $5 \mathrm{~min}$. The solution was then pelleted $(500 \mathrm{~g})$ and the absorbance at $532 \mathrm{~nm}$ of the resulting supernatant was measured in a spectrophotometer (model DU-30; Beckman Instruments, Inc., Palo Alto, CA). In some experiments the catalytic iron chelate FeNTA $(1-10 \mu \mathrm{M})$ was included in the reaction mixture to assure $\cdot \mathrm{OH}$ formation. All data from iron-loaded cells were analyzed against a paired negative (non-iron-loaded) control for that particular cell population. Because of variable amounts of adventitious iron in the buffer, the background value of the "negative" control varied somewhat.

Spin trapping. Spin trapping of macrophage-derived free radicals was performed using previously developed techniques $(16,20-22)$. AM or MDM $\left(2.5-5.0 \times 10^{6} / \mathrm{ml}\right)$ were suspended in HBSS containing $140 \mathrm{mM}$ DMSO (Fisher Scientific, Fairlawn, NJ), $0.1 \mathrm{mM}$ diethylenetriaminepentaacetic acid (DTPA; Sigma Chemical Co.) and either 100 mM 5,5 dimethyl-1-pyrroline- $N$-oxide (DMPO; Sigma Chemical Co.) or $10 \mathrm{mM} N$-t-butyl- $\alpha$-phenyl-nitrone (PBN; Sigma Chemical Co.) to a volume of $0.5 \mathrm{ml}$. Alternatively, in some experiments $10 \mathrm{mM} \alpha-(4-$ pyridyl-1-oxide)- $N$-t-butyl- $\alpha$-phenyl-nitrone (4-POBN; Sigma Chemical Co.) and $170 \mathrm{mM}$ ethanol was substituted for DMPO/PBN and DMSO, respectively. After the addition of desired macrophage stimulus the suspension was transferred to a flat quartz electron paramagnetic resonance spectrometry (EPR) cell and sequential EPR spectra were obtained at room temperature using an EPR spectrometer (model E104A, Varian Associates Inc., Palo Alto, CA or model ESP300,
Bruker, Karlsruhe, Germany). When indicated, ferrous ammonium sulfate $(0.1 \mathrm{mM})$, SOD ([ $30 \mathrm{U} / \mathrm{ml}$; Sigma Chemical Co.) or catalase ( $500 \mathrm{U} / \mathrm{ml}$; Sigma Chemical Co.) were included. In some experiments, the reaction of $400 \mu \mathrm{M}$ NADH (Sigma Chemical Co.) and $8 \mu \mathrm{M} \mathrm{N}$ methyl-1-hydroxyphenazine (pyocyanin) was employed as a continuous $\cdot \mathrm{O}_{2}^{-}$generating system (23). The latter compound was kindly provided by Dr. Charles Cox (University of Iowa, Department of Microbiology). Routinely, for the Varian instrument spectrometer, microwave power was $20 \mathrm{~mW}$, modulation frequency was $100 \mathrm{kHz}$ with a modulation amplitude of $1.0 \mathrm{G}$, response time was $1 \mathrm{~s}$, and the gain was $5 \times 10^{4}$. For experiments performed using the Bruker, microwave power was $40 \mathrm{~mW}$, modulation frequency was $100 \mathrm{kHz}$ with a modulation amplitude of $1.051 \mathrm{G}$, response time was $1.3 \mathrm{~s}$, and the gain was 1.0 $\times 10^{6}$.

In the DMPO spin trapping system, $\cdot \mathrm{O}_{2}^{-}$formation yields two principal spin adducts $\mathrm{DMPO} / \cdot \mathrm{OOH}\left(A_{\mathrm{N}}=14.3, A_{\mathrm{H}}=11.7 \mathrm{G}\right)$ and $\mathrm{DMPO} / \cdot \mathrm{OH}\left(A_{\mathrm{N}}=A_{\mathrm{H}}=14.9 \mathrm{G}\right)(16)$. Hydroxyl radical is spin trapped primarily as catalase inhibitable DMPO $/ \cdot \mathrm{CH}_{3}\left(A_{\mathrm{N}}=15.3, A_{\mathrm{H}}\right.$ $=22.0 \mathrm{G})(16)$. With the PBN/DMSO and 4-POBN/ethanol system, - $\mathrm{O}_{2}^{-}$generation does not result in a stable spin adduct whereas under aerobic conditions $\cdot \mathrm{OH}$ results in formation of single nitroxide species. In the case of PBN/DMSO this species $\left(A_{\mathrm{N}}=15.1, A_{\mathrm{H}}=3.5 \mathrm{G}\right)$ has been assigned to $\mathrm{PBN} / \cdot \mathrm{OCH}_{3}(20)$ whereas with 4-POBN/ethanol the resulting spin adduct $\left(A_{\mathrm{N}}=15.8, A_{\mathrm{H}}=2.7 \mathrm{G}\right)$ has been assigned to 4-POBN $/ \cdot \mathrm{CHOHCH}_{3}(21,22)$.

Protein and ferritin concentration. Protein concentration was determined according to the method of Lowry et al. (24). Ferritin measurements were made after sonication of cell samples using a commercial immunoradiometric assay manufactured by Bio-Rad Laboratories, Hercules, CA. The assay was performed by the Special Chemistry Laboratory, University of Iowa Hospitals and Clinics, Iowa City, IA, according to the manufacturer's instructional manual using human liver ferritin as a standard.

Iron determination. Buffer and cell-associated iron content were quantitated as previously described (8). Briefly, samples were incubated overnight at $110^{\circ} \mathrm{C}$ in nitric acid. $\mathrm{pH}$ was then raised to neutrality by addition of $\mathrm{NH}_{4} \mathrm{OH}$ and the samples were added to a mixture of ferrozine $(0.3 \%$; Sigma Chemical Co.) and ascorbic acid $(0.02 \%)$. Iron concentration was then quantitated as formation of the $\mathrm{Fe}^{+2}$-ferrozine complex $\left(\mathrm{A}_{562}\right)$ using a spectrophotometer.

Electron microscopy. Localization of cellular iron was assessed by electron microscopy using a modification of a previous methodology used for localizing intracellular iron storage components (25). The cells were fixed with $2.5 \%$ glutaraldehyde in $0.1 \mathrm{M}$ cacodylate buffer and stained with $1 \%$ acid ferrocyanide followed by post-treatment fixation in $1 \% \mathrm{OsO}_{4}$. The preparations were examined without counterstaining using a transmission electron microscope (Hitachi H-7000 Central Electron Microscopy Research Facility, University of Iowa) at an accelerating voltage of $50 \mathrm{kV}$ and magnification of 4,000 to 7,000.

Cell fractionation. To ascertain the location of cell-associated iron, mononuclear cells were cavitated under $350 \mathrm{psi} \mathrm{N}_{2}$ as previously described (26). The suspension was then centrifuged sequentially at 500 , 11,000 , and $100,000 \mathrm{~g}$ for $15 \mathrm{~min}$ at $4^{\circ} \mathrm{C}$. Each pellet was washed three times and resuspended to the same volume as initially present. Each pellet as well as the $100,000 \mathrm{~g}$ supernatant was then stored at $-80^{\circ} \mathrm{C}$. Iron content of both the membrane-containing pellet and the supernatant were determined using the ferrozine assay described above. Previous work using similar methodology (8) demonstrated that most mitochondria are present in the $11,000 \mathrm{~g}$ pellet, with the remainder in the $500 \mathrm{~g}$ pellet. Lysosomes are equally distributed through these fractions. To determine the location of the plasma membrane in this fractionation scheme, each pellet and the $100,000 \mathrm{~g}$ supernatant was evaluated for the presence of the heavy chain of Mol by Western blot using the technique and anti-Mol produced and kindly provided by Dr. William Nauseef (Department of Internal Medicine, University of Iowa) (27). Only the $11,000 \mathrm{~g}$ pellet and to a lesser extent the $500 \mathrm{~g}$ pellet was found to contain Mol immunoreactive protein. In contrast, the cytosolic marker enzyme lactate dehydrogenase was only detectable in the 
$100,000 \mathrm{~g}$ supernatant using our previous methodology ( 8 ). Thus, the $500 \mathrm{~g}$ pellet appears to contain whole cells and partially disrupted cell constituents. The $11,000 \mathrm{~g}$ pellet contains the majority of mitochondria, essentially all plasma membrane, and significant lysosomes. The $100,000 \mathrm{~g}$ supernatant should contain all cytosolic components.

Gel electrophoresis and immunoblot analysis. Cell samples were sonicated for $15 \mathrm{~s}$ and solubilized $\left(100^{\circ} \mathrm{C}, 5 \mathrm{~min}\right)$ in Laemmli solubilizing buffer containing $1 \%$ 2-mercaptoethanol. Samples were then applied to a $14 \%$ acrylamide SDS-PAGE minigel. Gels were then either stained with silver (28) or transferred to nitrocellulose (29). Resulting nitrocellulose blots were overlaid with one of the following: rabbit polyclonal antisera; antihuman kidney manganese superoxide dismutase (MnSOD); recombinant human placenta copper zinc superoxide dismutase (CuZnSOD); human erythrocyte glutathione peroxidase; or bovine liver catalase, each of which were generated and kindly provided by Dr. Larry Oberley (University of Iowa Radiation Research Laboratory, Iowa City, IA). After $4 \mathrm{~h}$ of incubation the blots were washed, incubated with alkaline phosphatase conjugated $F\left(a b^{\prime}\right) 2$ fragment goat anti-rabbit IgG (Sigma Chemical Co.), washed again, and developed by the addition of 5-bromo-4-chloro-3-indoyl-phosphate and nitroblue tetrazolium (29).

The presence of heat-shock protein 70 ( HSP70) was investigated by addition to the nitrocellulose blots of a commercially available rat monoclonal anti-Drosophila HSP70 antibody (Affinity Bioreagents, Deerfield, IL). The blots were washed, incubated with peroxidase-conjugated goat polyclonal anti-rat IgG, washed, and developed by the addition of the peroxidase substrate according to the method of Ogata (30).

Other reagents. Zymosan A was obtained from Sigma Chemical Co. and opsonized by incubation for $30 \mathrm{~min}$ at $37^{\circ} \mathrm{C}$ in $100 \% \mathrm{AB}(+)$ or pooled normal human serum after which it was washed twice and maintained on ice in HBSS until usage. Final concentration employed in all assays was $3 \mathrm{mg} / \mathrm{ml}$. PMA was obtained from Sigma Chemical Co., diluted in DMSO, and added to macrophage suspensions to a final concentration of $100 \mathrm{ng} / \mathrm{ml}$.

Statistical analysis. A paired Student's $t$ test was used for all statistical analyses in which untreated cells from the same donor served as the paired control. Results were considered significant at $P<0.05$.

\section{Results}

Spin trapping of free radicals formed by stimulated AM. Spin trapping is a highly sensitive and specific means of identifying free radicals formed in biological systems (31). Multiple different spin trapping agents have been developed, each of which has their own advantages and limitations $(31,32)$. Of those systems available, the one composed of a combination of 4POBN and ethanol appears to be the most sensitive for the detection of $\cdot \mathrm{OH}(21,22)$. Accordingly, AM were obtained from smoker and nonsmoker human volunteers by BAL and suspended in HBSS containing DTPA, 4-POBN, and ethanol. DTPA was included to decrease confounding effects of adventitious iron in the system. PMA was added to the suspensions to initiate the phagocyte respiratory burst, after which sequential EPR spectra were obtained. No evidence of the 4-POBN/ - $\mathrm{CHOHCH}_{3}$ spin adduct, which would be generated in the presence of $\cdot \mathrm{OH}$, was detected unless exogenous iron was added to the system (Fig. 1). Substitution of other spin trapping systems previously employed for the detection of phagocyte-derived - OH (DMPO/DMSO and PBN/DMSO) or the use of opsonized zymosan as the stimulus also failed to yield evidence of $\cdot \mathrm{OH}$ formation in the absence of iron supplementation (not shown).

Confirmation of the lack of hydroxyl radical formation by $A M$. Although the results of the three spin trapping techniques provided strong evidence for the lack of $\cdot \mathrm{OH}$ generation by

\section{PMA + 4-POBN/EtOH}

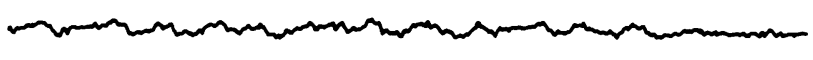

PMA + Fe + 4-POBN/EtOH

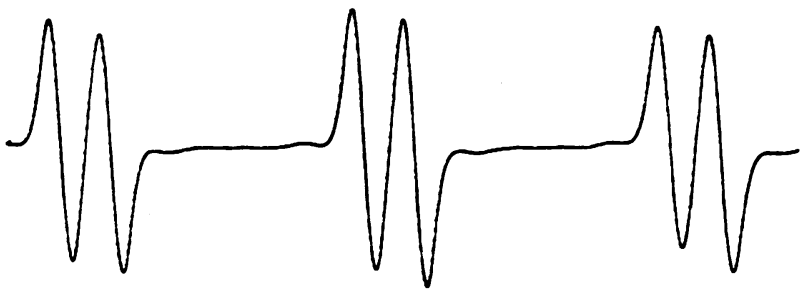

Figure 1. Spin trapping of free radicals formed by stimulated AM from smokers. Shown are two EPR tracings obtained after PMA stimulation of AM from smokers in the presence of 4-POBN, ethanol, and DTPA in the absence or presence of exogenous iron $(0.1 \mathrm{mM})$. In the presence of iron the 4-POBN/ $\cdot \mathrm{CHOHCH}_{3}$ spin adduct was detected indicating $\cdot \mathrm{OH}$ production. Results are representative of experiments performed with AM from three separate donors. Identical results were obtained using AM from nonsmokers.

AM regardless of smoking status, we sought to confirm our results using an alternative $\cdot \mathrm{OH}$ detection system. The reaction of $\cdot \mathrm{OH}$ with 2-deoxyribose results in formation of oxidation products that, when exposed to TBA and boiled, yield a chromagen with a characteristic absorbance maximum at 532 $\mathrm{nm}(17-19)$. Since neither $\cdot \mathrm{O}_{2}^{-}$nor $\mathrm{H}_{2} \mathrm{O}_{2}$ lead to formation of such a chromagen, formation of TBA-reactive deoxyribose oxidation products has been used as a sensitive and relatively specific means of quantitating the production of $\cdot \mathrm{OH}$.

Accordingly, AM from smokers and nonsmokers were stimulated with PMA or opsonized zymosan in the presence of 2-deoxyribose. After a 40 -min incubation at $37^{\circ} \mathrm{C}$, cells were pelleted and the presence of TBA reactive oxidation products was determined in the supernatant. As shown in Table I, unless

Table I. Formation of Hydroxyl Radical by Alveolar Macrophages From Smokers and Nonsmokers

\begin{tabular}{lcc}
\hline & Smokers & Nonsmokers \\
\hline Unstimulated & $0.016 \pm 0.006$ & $0.012 \pm 0.002$ \\
PMA & $0.027 \pm 0.003$ & $0.035 \pm 0.008$ \\
OZ & $0.022 \pm 0.009$ & ND \\
PMA + FeNTA & $0.172 \pm 0.015$ & $0.166 \pm 0.021$ \\
OZ + FeNTA & $0.177 \pm 0.067$ & ND \\
\hline
\end{tabular}

PMA and opsonized zymosan $(\mathrm{OZ})$-stimulated ${ }^{\circ} \mathrm{OH}$ formation by AM of smokers and nonsmokers in the presence and absence of added FeNTA. Data are the mean \pm SEM $A_{532}$ of duplicate samples from three separate experiments whereby ${ }^{\circ} \mathrm{OH}$ generation was assessed using the formation of TBA-reactive 2-deoxyribose oxidation products. The slight increase in $\mathrm{A}_{532}$ observed after PMA and $\mathrm{OZ}$ stimulation of $A M$ in the absence of exogenous iron was not significantly different from unstimulated AM $(P>0.05)$. This increase is expected from the presence of adventitious iron in the buffer as a similar $A_{532}$ was generated during the reaction of hypoxanthine and xanthine oxidase in the same buffer. This reaction does not generate ${ }^{\circ} \mathrm{OH}$ in the absence of exogenous iron $(78,79)$. ND, not determined. 
a catalytic iron chelate (FeNTA) was included in the reaction mixture, no evidence of $\cdot \mathrm{OH}$ generation was detectable.

Evidence for catalytic iron complexes in airway lavage fluid and their uptake by $A M$. The above data are consistent with the hypothesis that intracellular sequestration of iron by AM may decrease the potential for extracellular $\cdot \mathrm{OH}$ generation resulting from the presence of catalytic iron complexes within the airway. Indirect evidence has suggested that catalytic iron complexes contained in cigarette smoke may be deposited in the airway and contribute to cigarette-associated lung injury (9, $33,34)$. However, direct evidence for catalytic iron in airway fluids has not previously been obtained. Accordingly, we exposed BAL samples from which cellular components had been removed to a chemical $\cdot \mathrm{O}_{2}^{-} / \mathrm{H}_{2} \mathrm{O}_{2}$ generating system. Evidence for $\cdot \mathrm{OH}$ generation was sought using the 4-POBN/ethanol spin trapping system. $\cdot \mathrm{OH}$ production was demonstrable using BAL from either smokers $(n=5)$ or nonsmokers $(n=2)$ (Fig. 2). Preincubation of the BAL with the iron chelator deferoxamine $(0.5 \mathrm{mM} \times 2 \mathrm{~h})$ decreased the magnitude of $\cdot \mathrm{OH}$ generation by $80 \%$, suggesting that an iron catalyst present in the BAL was responsible for the ability of the samples to induce - OH generation. Although the normal saline used for the lavage also resulted in some $\cdot \mathrm{OH}$ formation, this was considerably below levels observed with the BAL fluid. Somewhat surprisingly, there appeared to be little difference between the amount of $\cdot \mathrm{OH}$ catalyzed by smoker and nonsmoker BAL.

The observations that cell-free lavage fluid can contribute to $\cdot \mathrm{OH}$ formation whereas intracellular iron present in isolated AM cannot suggests that AM may limit the steady state concentration of catalytic iron complexes in the airway. To further examine this possibility, the ability of AM to decrease the ability of the BAL samples to catalyze $\cdot \mathrm{OH}$ generation was evaluated. AM $\left(2 \times 10^{6} / \mathrm{ml}\right)$ were added to BAL samples and the suspension incubated at $37^{\circ} \mathrm{C}$ for $30 \mathrm{~min}$. The cells were removed and the resulting BAL supernatant was added to the $\cdot \mathrm{O}_{2}^{-} / \mathrm{H}_{2} \mathrm{O}_{2}$ generating system. Hydroxyl radical generation was then quantitated by spin trapping. As shown in Fig. 2, exposure to AM resulted in a marked decrease in the ability of the BAL to catalyze $\cdot \mathrm{OH}$ formation $(n=5)$.

In contrast to results that would have been predicted from our studies with AM from smokers (Fig. 1), PMA stimulation of AM that had been incubated in BAL demonstrated the ability to generate $\cdot \mathrm{OH}$ (Fig. 3). This suggested that the duration of time after exposure to catalytic iron complexes might be an important factor in determining whether iron-exposed AM generated $\cdot \mathrm{OH}$ upon subsequent stimulation. To examine this possibility it would be necessary to study AM at various time points after BAL exposure. Unfortunately, we have found that viability of AM, particularly those obtained from cigarette smokers, decreases rapidly when placed in cell culture (McGowan, S. E., unpublished observation ). Furthermore, the heterogeneous nature of the AM population obtained from the airway in terms of age, metabolic status, etc., could conceivably confound data interpretation. We have previously shown that, like AM, MDM also lack the endogenous capacity to generate - $\mathrm{OH}(16,20)$ and these cells in many ways resemble tissue macrophages. In addition, when used from a single donor they provide a uniform cell population for study. Therefore, we assessed whether MDM generated under in vitro growth conditions could be used to address the above question. Consistent with the AM results we found that exposure of BAL to MDM resulted in a diminution of the ability of the BAL to act as an

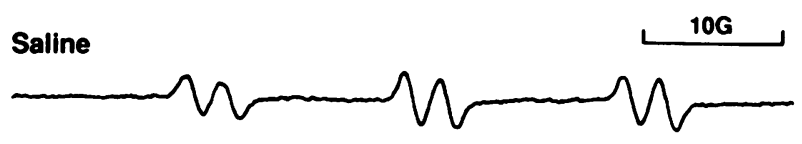

Smoker's BAL before AM

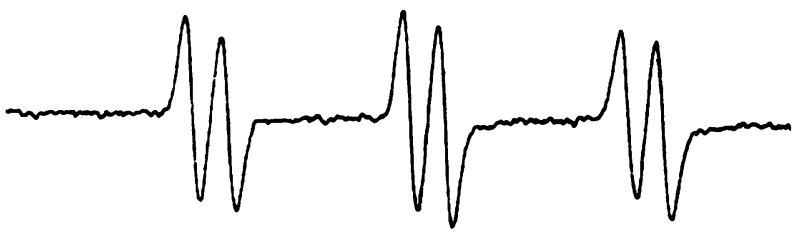

Smoker's BAL after AM

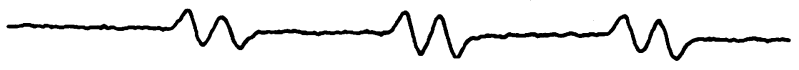

Non-smoker's BAL before AM

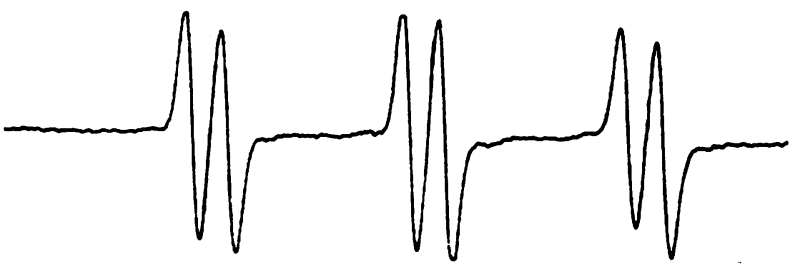

Non-smoker's BAL after AM

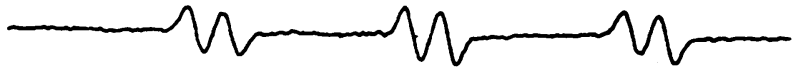

Figure 2. Spin trapping of hydroxyl radical catalyzed by BAL fluid. Shown are EPR spectra representing 4-POBN/ $\mathrm{CHOHCH}_{3}$ and therefore $\cdot \mathrm{OH}$ formation, resulting from the incubation of the $\mathrm{N}$ methyl-1-hydroxyphenazine/NADH $\cdot \mathrm{O}_{2}^{-} / \mathrm{H}_{2} \mathrm{O}_{2}$ generating system in the presence of $10 \mathrm{mM} 4-\mathrm{POBN}, 170 \mathrm{mM}$ ethanol, and $0.1 \mathrm{mM}$ DTPA in the stock saline solution routinely used for BAL; BAL from a smoker; the same smoker BAL sample, which had been incubated for $30 \mathrm{~min}$ in the presence of AM as per methods; BAL from a nonsmoker; and the same nonsmoker BAL, which had been incubated for $30 \mathrm{~min}$ in the presence of AM. BAL from both smokers and nonsmokers induced similar increases in $\cdot \mathrm{OH}$ generation relative to the normal saline control. This ability of the BAL fluid to act as an $\cdot \mathrm{OH}$ catalyst was decreased by exposure to AM. Results are representative of experiments performed with BAL samples obtained from five smokers and two nonsmokers.

- OH catalyst (not shown) and that these BAL-exposed MDM acquired the ability to generate $\cdot \mathrm{OH}$ upon stimulation with PMA (Fig. 3). When these BAL-exposed MDM were allowed to remain in culture, after $5 \mathrm{~d}$ they would no longer generate - OH when stimulated by PMA (Fig. 3).

Effect of increasing iron content of MDM on subsequent hydroxyl radical formation. The above data are consistent with an alteration in the site and/or reactivity of catalytic iron taken up from BAL fluid by macrophages over time. Further study of the acquisition of this catalytic iron was limited by the fact that BAL contains a heterogeneous group of iron complexes that are present in relatively low concentrations $(35,36)$. Accordingly, experimental conditions were developed whereby MDM with increased cellular iron content could be generated using well-defined catalytic iron chelates. MDM were incubated in $0.5 \mathrm{mM}$ FeNTA, FeADP, or Fe-citrate for $30 \mathrm{~min}$ at $37^{\circ} \mathrm{C}$ followed by repetitive washing. This resulted in an increase in cellular iron content from $3.2 \pm 0.3$ to $24.8 \pm 1.8,47.0 \pm 0.2$, and $18.3 \pm 1.8 \mathrm{nmol} / 10^{6}$ cells, respectively (mean $\pm \mathrm{SEM}, n=3, P$ 


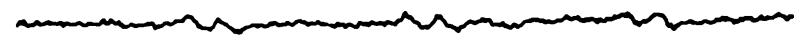

$A M+B A L$

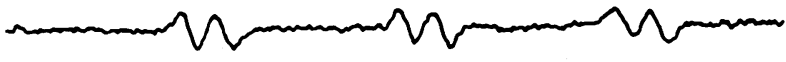

MDM

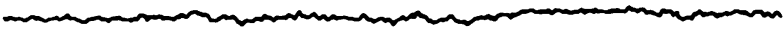

MOM + BAL

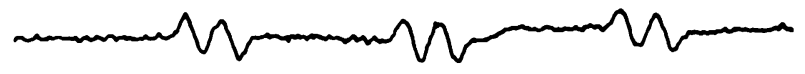

MOM + BAL after additional 5 days in culture

Figure 3. Spin trapping of hydroxyl radical generated by AM and MDM exposed to BAL fluid. The first four EPR spectra are those resulting from PMA stimulation in the presence of 4-POBN, ethanol, and DTPA of AM and MDM previously incubated in normal saline or BAL from a smoker for $30 \mathrm{~min}(+\mathrm{BAL})$ and then washed. The bottom spectrum was performed using the same cells as in the fourth spectrum except they had been allowed to remain in culture an additional $4 \mathrm{~d}$. AM or MDM incubated in the presence of BAL acquired the ability to generate $\cdot \mathrm{OH}$ upon stimulation with PMA. In the case of MDM this capacity was lost after $5 \mathrm{~d}$ in culture. Similar results were obtained regardless of whether the BAL was derived from smokers (five samples) or nonsmokers (two samples).

$<0.05$ for each of the conditions). These levels are similar to those of AM from smokers $(7,8)$. As seen with BAL-exposed MDM, when these acutely FeNTA or FeADP iron-overloaded cells were stimulated with PMA, evidence of $\cdot \mathrm{OH}$ formation was readily detectable by spin trapping using the 4-POBN/ethanol system (see Fig. 4). No spin adducts were detectable with either the DMPO/DMSO or PBN/DMSO systems, likely related to the increased sensitivity of the 4-POBN/ethanol system for $\cdot \mathrm{OH}(21,22)$. In addition, no evidence of $\cdot \mathrm{OH}$ was observed following PMA stimulation of MDM or AM acutely loaded with Fe-citrate with any of the three spin trapping techniques ( not shown). Of note, stimulation of control MDM in the presence of $20 \mu \mathrm{M} \mathrm{Fe}$-citrate also failed to generate $\cdot \mathrm{OH}$ as detected by the 4-POBN/ethanol system.

As confirmation of the above data, experiments were again repeated using the deoxyribose oxidation assay. PMA stimulation of MDM acutely loaded with FeNTA, FeADP, or Fe-citrate yielded $\mathrm{A}_{532}$ of $0.107 \pm 0.024,0.029 \pm 0.001$, and $0.017 \pm 0.001$, respectively. In each case these values were significantly greater than the respective control (unloaded) MDM ( $n$ $=3, P<0.05$ for each conditions by paired $t$ test ).

Effects of acute versus chronic MDM iron overload. As noted above, among the potential factors accounting for the generation of $\cdot \mathrm{OH}$ by acutely iron-overloaded MDM and AM but not AM from smokers with similar levels of cell-associated iron is the duration of time between iron exposure and quantitation of $\cdot \mathrm{OH}$ generation. To examine this variable, mononuclear phagocytes were iron loaded by exposure to $0.5 \mathrm{mM}$ FeNTA, FeADP, or Fe-citrate for $30 \mathrm{~min}$. They were then allowed to remain in culture for an additional $5 \mathrm{~d}$. These cells were termed chronic iron-overloaded MDM. Exposure to FeNTA and FeADP resulted in cells whose iron content was considerably increased relative to control cells (Table II and Table III). For FeNTA- and FeADP-loaded cells, total cellular iron content decreased only $32-35 \%$ over days $1-5$ of incubation after iron exposure ( Table II and Table III). Even with this decrease, the iron content of the FeNTA- and FeADP-loaded cells was 10 - and 25-fold higher, respectively, than a control cell population. In contrast to these data, by $24 \mathrm{~h}$ of culture, the iron content of the Fe-citrate-loaded cells reverted to levels that were no different from control cells (Table III). As assessed with the deoxyribose assay, the magnitude of $\cdot$ OH generation after PMA stimulation of the iron-loaded cells decreased with their time in culture independent of the iron chelate with which they were initially loaded (Table II and Table III). Surprisingly, at day 1 the Fe-citrate-loaded cells exhibited greater - OH generation than the control cells in spite of similar levels of cellular iron ( Table III). By day 5 in culture, $\cdot \mathrm{OH}$ formation by all iron-loaded MDM was not statistically different from control (non-iron-treated ) cells ( Table II and Table III). Stimulation of control and chronic iron-overloaded MDM with PMA in the presence of freshly added FeNTA yielded similar magnitudes of $\cdot \mathrm{OH}$ (data not shown), suggesting that the chronic iron-overloaded MDM did not lose their ability to generate $\cdot \mathrm{O}_{2}^{-}$and / or $\mathrm{H}_{2} \mathrm{O}_{2}$.

Consistent with the above results, no evidence of $\cdot \mathrm{OH}$ was detected by 4-POBN/ethanol spin trapping when chronic ironoverloaded MDM were stimulated with PMA regardless of whether they were loaded with FeNTA, FeADP, or Fe-citrate.

Table II. Iron Content of Subcellular Fractions and ${ }^{\bullet} \mathrm{OH}$ Generation by FeNTA-loaded MDM as a Function of Time in Culture

\begin{tabular}{cccccc}
\hline $\begin{array}{c}\text { Days in } \\
\text { culture }\end{array}$ & $\begin{array}{c}\text { Iron content } \\
\text { whole MDM }\end{array}$ & $\mathrm{OH}$ & $\begin{array}{c}\text { Iron content } \\
11,000 \mathrm{~g} \\
\text { pellet }\end{array}$ & $\begin{array}{c}\text { Iron content } \\
100,000 \mathrm{~g} \\
\text { pellet }\end{array}$ & $\begin{array}{c}\text { Iron content } \\
\text { supernatant }\end{array}$ \\
\hline 1 & $41.992 \pm 0.098$ & $0.098 \pm 0.003$ & $11.872 \pm 2.176$ & $0.433 \pm 0.069$ & $2.166 \pm 0.088$ \\
3 & $29.334 \pm 2.177$ & $0.044 \pm 0.008$ & $6.722 \pm 1.535$ & $1.724 \pm 0.484$ & $4.767 \pm 1.010$ \\
5 & $26.944 \pm 1.857$ & $0.029 \pm 0.004$ & $7.944 \pm 2.800$ & $5.944 \pm 3.028$ & $6.333 \pm 1.642$
\end{tabular}

Total cellular iron content ( $\mathrm{nmol} / 10^{6}$ cells) and PMA-stimulated hydroxyl radical generation detected by the deoxyribose oxidation assay $\left(\mathrm{A}_{532}\right)$ of MDM as a function of days in culture after acute iron exposure of 5-d-old MDM to FeNTA in comparison to paired cells that were not iron treated. Also shown is change in the iron content ( $\mathrm{nmol} / 10^{6}$ cells) over time of subcellular fractions of these same cells. Data are the mean of three separate experiments. 
Table III. Iron Content of Subcellular Fractions and ${ }^{\bullet} \mathrm{OH}$ Generation over Time from MDM Loaded with Iron Bound to FeADP or Fe-Citrate

\begin{tabular}{|c|c|c|c|c|c|}
\hline Days in culture & $\begin{array}{l}\text { Iron content } \\
\text { whole MDM }\end{array}$ & ${ }^{\circ} \mathrm{OH}$ & $11,000 \mathrm{~g}$ pellet & $100,000 \mathrm{~g}$ pellet & Supernatant \\
\hline \multicolumn{6}{|l|}{ FeADP } \\
\hline 1 & $9.580 \pm 1.277$ & $0.058 \pm 0.007$ & 0.884 & 0.429 & 0.671 \\
\hline 2 & $9.059 \pm 1.646$ & $0.025 \pm 0.005$ & 0.796 & 1.167 & 2.432 \\
\hline 3 & $6.509 \pm 1.137$ & $0.011 \pm 0.007$ & 0.648 & 1.735 & 1.267 \\
\hline \multicolumn{6}{|l|}{ Fe-citrate } \\
\hline 1 & $1.457 \pm 0.095$ & $0.038 \pm 0.003$ & 0.173 & 0.162 & 0.256 \\
\hline 2 & $1.637 \pm 0.588$ & $0.003 \pm 0.003$ & 0.360 & 0.580 & 0.680 \\
\hline 3 & $0.971 \pm 0.105$ & $0.002 \pm 0.001$ & 0.422 & 0.578 & 0.489 \\
\hline
\end{tabular}

Total cellular iron content ( $\mathrm{nmol} / 10^{6}$ cells) and PMA-stimulated hydroxyl radical generation detected by the deoxyribose oxidation assay $\left(\mathrm{A}_{532}\right)$ of MDM as a function of days in culture after acute iron exposure of monocytes to FeADP or Fe-citrate in comparison to paired cells that were not iron treated. Also shown is change in the iron content ( $\mathrm{nmol} / 10^{6}$ cells) over time of subcellular fractions obtained from these same cells. Movement of iron from the $11,000 \mathrm{~g}$ (membrane-containing) pellet to the $100,000 \mathrm{~g}$ pellet and supernatant (cytosol) was observed over time. Results are the mean of triplicate samples from three separate experiments. Note that the values from the individual fractions for each day sometimes give the appearance of an increase in total cellular iron content over time (e.g., FeADP and Fe-citrate). However, the variability from day to day of the effectiveness of the cavitation, as reflected by the iron content of the $500 \mathrm{~g}$ pellet (not shown), makes such interpretation invalid.

These data contrast the clear evidence of $\cdot \mathrm{OH}$ formation obtained with acutely FeNTA- or FeADP-loaded MDM (Fig. 4) in spite of their similar total iron content.

Translocation of cell-associated iron. One possible mechanism for the loss of $\cdot \mathrm{OH}$ generation in the chronically ironoverloaded MDM is movement of the cell-associated iron to a different cellular location. Therefore, MDM that had been previously incubated in FeNTA, FeADP, or Fe-citrate and placed in cell culture were periodically harvested and subcellular fractions obtained. Determination of the iron content of these subcellular fractions showed that there was a gradual translocation of the cell-associated iron from the plasma membrane-containing fraction $(11,000 \mathrm{~g}$ pellet $)$ to the cytosol $(100,000 \mathrm{~g} \mathrm{su}-$ pernatant) as well as the $100,000 \mathrm{~g}$ pellet independent of the iron chelate with which the cells were loaded (Tables II and III). The timing of the iron movement corresponded closely to the decrease in - OH generation of PMA-stimulated cells ( Tables II and III), suggesting that the iron became less available as a catalyst for Haber-Weiss reaction with internalization.

This phenomenon was further evaluated by electron microscopy using cells loaded with FeNTA as the model system. When cells were stained for iron, electron microscopy revealed that, in contrast to acutely iron-overloaded MDM and control (non-iron-loaded) MDM, iron-containing aggregates were demonstrable in the cytosol of chronic iron-overloaded MDM (Fig. 5).

Intracellular iron in most cells is stored within the cytosol as ferritin. Previous work (8) suggested that an increase in macrophage iron content should result in an increase in ferritin content as well. Consistent with this literature the ferritin content of chronic iron-overloaded cells that had been exposed to FeNTA as 5-d-old MDM and then allowed to remain in culture for an additional $5 \mathrm{~d}$ was 273.5 compared with $82.1 \mathrm{ng}$ ferritin/ $10^{6}$ cells in non-iron-exposed controls. Similarly, after $5 \mathrm{~d}$ in culture, the ferritin content of MDM that had been exposed to FeNTA as monocytes was nearly nine times higher than the same population of MDM that were not previously exposed to FeNTA: $438.1 \pm 198.5$ compared with $51.8 \pm 14.8 \mathrm{ng}$ ferritin/ $10^{6} \operatorname{MDM}(n=5)$. In the control cell population $91 \%$ of the ferritin detected was in the $100,000 \mathrm{~g}$ supernatant. In contrast, the $100,000 \mathrm{~g}$ supernatant contained only $65 \%$ of the ferritin in the chronically iron overloaded MDM as detected by radioimmunoassay. The remainder was present in the $100,000 \mathrm{~g}$ pellet.

Effect of iron overload on MDM antioxidant defenses. An alternative mechanism(s) that could also contribute to the decrease in $\cdot \mathrm{OH}$ generation by iron-overloaded MDM over time would be if the process caused increased levels of one or more antioxidant enzymes. Therefore, levels of MnSOD, CuZnSOD, catalase, and glutathione peroxidase in 5-d-old control and MDM acutely and chronically iron-overloaded with FeNTA were quantitated by immunoblot. No differences in any antioxidant enzyme levels were observed among the three cell populations (Fig. 6).

Acute iron exposure likely places cells under increased oxidative stress. Such oxidant stress induces the production of a group of proteins termed heat-shock proteins (e.g., heat-shock protein 70 [HSP-70]) in a variety of eukaryotic and prokaryotic systems (37). This response appears to confer protection from such exposures (37). Therefore, we examined whether in vitro iron overload induced the heat shock response in MDM. However, neither control nor acutely or chronically ironloaded MDM exhibited detectable levels of HSP-70 as assessed by immunoblot (data not shown). Silver-stained SDS-PAGE of each of these cell populations also showed no apparent difference in protein profile (data not shown).

\section{Discussion}

Alveolar macrophages from smokers contain considerably more iron than those of nonsmokers (7-9), presumably the result of AM ingestion of iron contained in cigarette smoke $(12,38)$ or alternatively as a consequence of the release of intracellular iron stores by local cells damaged by smoke constituents (9). Since some iron chelates catalyze the formation of $\cdot \mathrm{OH}$ (39) from $\cdot \mathrm{O}_{2}^{-}$and $\mathrm{H}_{2} \mathrm{O}_{2}$ and $\cdot \mathrm{OH}$ production has been incriminated in the pathogenesis of several forms of pulmonary injury (40-44), we examined whether AM from 


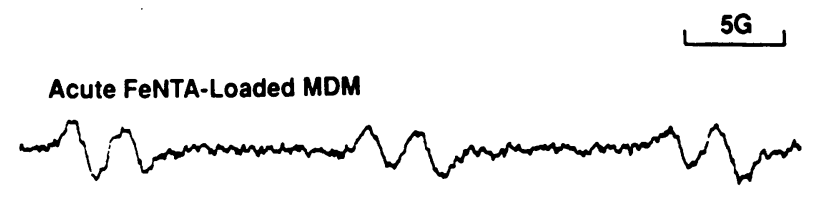

Chronic FeNTA-Loaded MDM
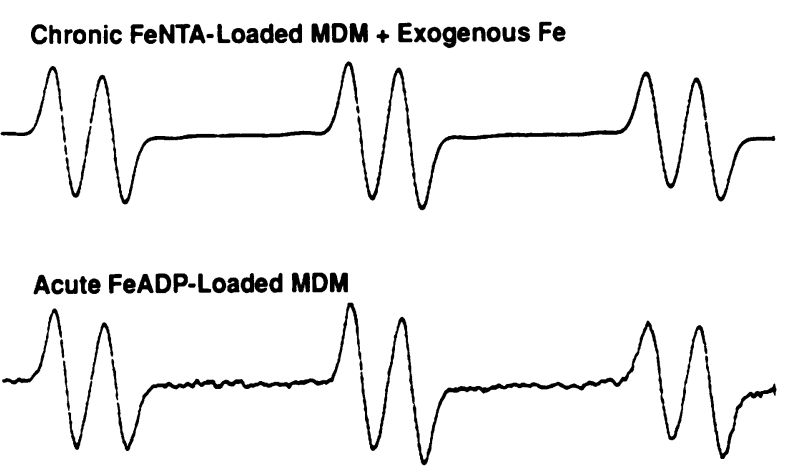

Chronic FeADP-Loaded MDM
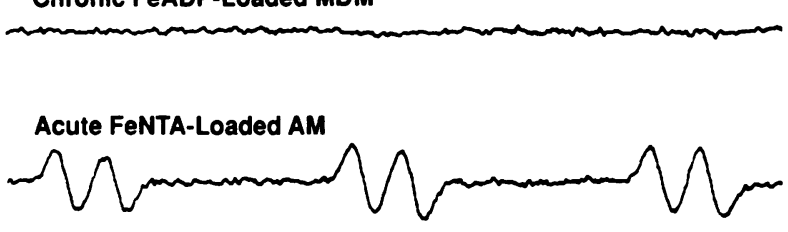

Acute FeADP-Loaded AM

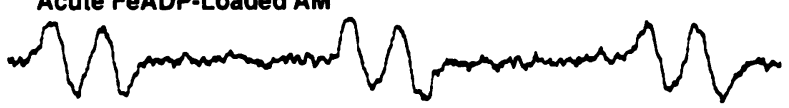

Figure 4. Spin trapping with 4-POBN/ethanol of free radicals generated by MDM and AM after acute overloading with various low molecular weight iron chelates. The first and fourth EPR spectra are tracings of MDM that had been acutely loaded with FeNTA or FeADP as per methods, after which the cells were stimulated with PMA in the presence of $10 \mathrm{mM}$ 4-POBN, $170 \mathrm{mM}$ ethanol, and 0.1 mM DTPA. Spectra observed with the FeNTA- and FeADP-loaded cells is that of 4-POBN $/ \cdot \mathrm{CHOHCH}_{3}$ consistent with $\cdot \mathrm{OH}$ formation. The second and fifth scans are tracings obtained under the same conditions except that the MDM had been loaded with FeNTA or FeADP as monocytes and placed in culture for an additional $5 \mathrm{~d}$ to allow differentiation to MDM (chronic MDM). No evidence of $\cdot \mathrm{OH}$ production was detected. The third scan was obtained when these same chronic FeNTA-loaded MDM were PMA stimulated in the presence of exogenous iron $(0.1 \mathrm{mM})$. Hydroxyl radical formation was detected, demonstrating the ability of these chronic MDM to generate . $\mathrm{OH}$ when an active iron catalyst was present. The bottom two scans are those obtained after PMA stimulation of AM from smokers recently loaded with either FeNTA or FeADP. Evidence of $\cdot$ OH production was detected in contrast to non-iron-loaded AM (Fig. 1). Negative results were again obtained with Fe-citrate-loaded AM. Results shown are representative of those obtained with studies of MDM from three separate subjects and of AM from two subjects.

smokers differed from those of nonsmokers in their capacity for $\cdot \mathrm{OH}$ generation.

Using three different spin trapping systems as well as the deoxyribose oxidation assay we found no evidence for the formation of $\cdot \mathrm{OH}$ by AM from either smokers or nonsmokers in the absence of an exogenous iron chelate. These data are similar to those obtained in recent spin trapping studies of MDM $(16,20,22)$. Yet they contrast conclusions reached in other studies of macrophages, including human AM (45-52). The reason for the discrepancy among these studies is not totally clear. However, the specificity of the systems employed in studies reporting detection of $\cdot \mathrm{OH}$ has been questioned (53) and the possibility that $\cdot \mathrm{OH}$ formation could have been the consequence of adventitious iron in the buffers employed (54) has not been addressed.

Failure to detect $\cdot \mathrm{OH}$ after stimulation of $\mathrm{AM}$ from smokers was not entirely surprising since their increased iron content is related to increased intracellular stores of both insoluble iron (possibly hemosiderin) and ferritin (8), predominantly of the L-type (55). Although both ferritin and hemosiderin have been reported to catalyze $\cdot \mathrm{OH}$ formation $(56,57)$, iron bound to both compounds is considerably less reactive than other iron chelates. Therefore, apoferritin has been suggested to serve an antioxidant function in some cells $(58,59)$. Furthermore, the exposure of intracellular iron chelates to $\cdot \mathrm{O}_{2}^{-}$ and $\mathrm{H}_{2} \mathrm{O}_{2}$ generated by the respiratory burst is likely low since $\mathrm{H}_{2} \mathrm{O}_{2}$ and $\cdot \mathrm{O}_{2}^{-}$are secreted extracellularly and $\mathrm{AM}$ antioxidant systems would markedly limit the intracellular concentration of these species. These data suggest that sequestration of extracellular iron, derived from cigarette smoke or damaged cells, within the AM may protect surrounding tissue from $\cdot \mathrm{OH}$-associated injury.

Consistent with the above hypotheses we demonstrated that BAL fluid contained substances capable of catalyzing . OH formation and that AM, as well as MDM, have the capacity to rapidly remove this catalytic iron from BAL fluid. The exact nature of the iron complex in $\mathrm{BAL}$ responsible for $\cdot \mathrm{OH}$ generation is unclear. Pertinent to cigarette smokers, aqueous extracts of cigarette smoke can generate $\cdot \mathrm{OH}$ via the metal ( Fe)-catalyzed decomposition of $\mathrm{H}_{2} \mathrm{O}_{2}(33)$ and a tobacco constituent $(\mathrm{s})$ has the capacity to mobilize iron from other biomolecules forming new iron complexes (34). Our ability to detect - OH generation after stimulation of AM recently exposed to BAL, FeNTA, or FeADP emphasizes the importance of the storage of this iron within the macrophage as a means of preventing extracellular $\cdot \mathrm{OH}$ generation. The fact that BAL samples from both smokers and nonsmokers contain catalytic iron complexes suggests that this process is dynamic and only decreases the steady state concentration of catalytic iron chelates rather than eliminates them from the airway. The increased number of AM in the airways of cigarette smokers may in part explain our somewhat surprising finding that BAL from smokers has no greater capacity for $\cdot \mathrm{OH}$ catalysis than that of nonsmokers in spite of the fact that the iron concentration of the lower respiratory tract in smokers is increased relative to nonsmokers (9).

Although the above process may be favorable from the standpoint of local tissue injury, it is worth noting that an increase in AM intracellular iron may also prove deleterious by enhancing the ability of certain pathogenic microorganisms to survive and replicate within macrophages (60-62). In addition, because of uncertainty as to the sensitivity of spin trapping and the deoxyribose assay for detecting $\cdot \mathrm{OH}$ formed within cells, our results do not eliminate the possibility of increased intracellular $\cdot \mathrm{OH}$ generation in $\mathrm{AM}$ from smokers. Although this should not damage surrounding tissues, it could contribute to the dysfunction observed in some studies of AM from smokers (63).

Results obtained with MDM suggest that the ability to sequester iron is not unique to AM but may be a property of 

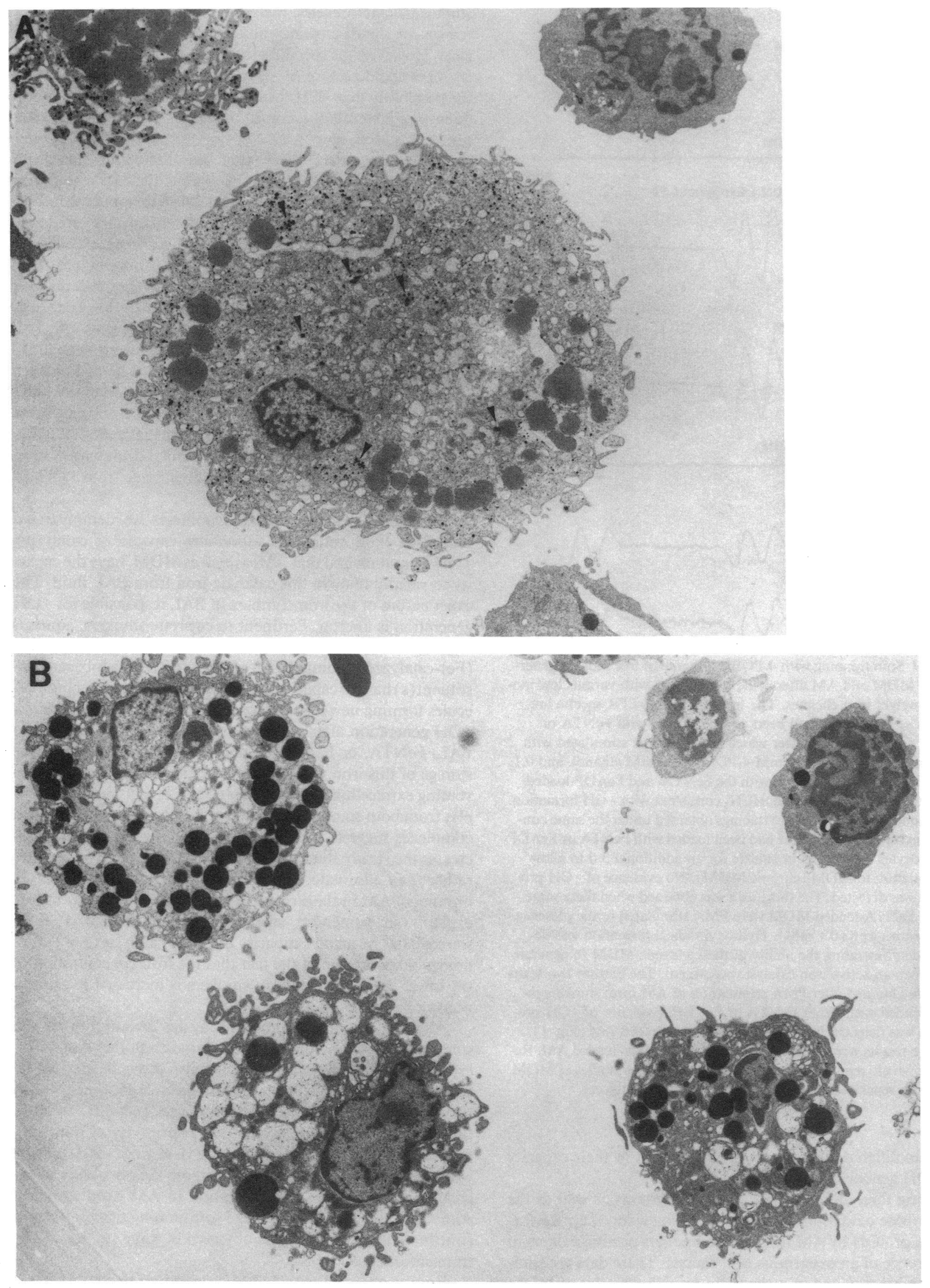

Figure 5. 


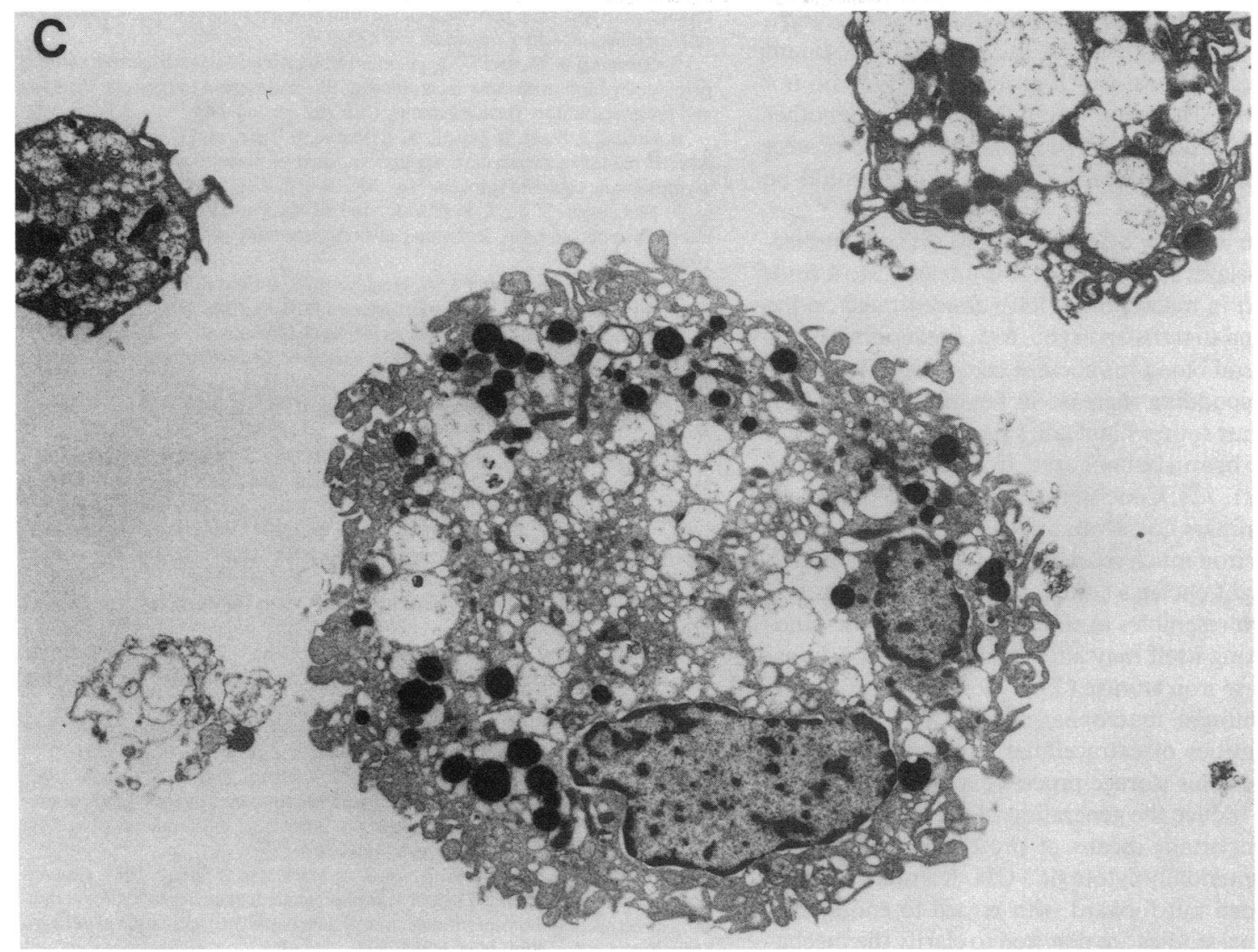

Figure 5. Localization of iron in iron-overloaded MDM. Electron microscopy of MDM stained with acid ferrocyanide to reveal iron location (see Methods). Opposite page: Shown are electron micrographs viewed at an accelerating voltage of $50 \mathrm{kV}$ of $(A) \mathrm{MDM}$ after chronic iron exposure of $5 \mathrm{~d}, \times 5,000$. (B) 5-d-old MDM after acute iron exposure, $\times 4,200$. Above: $(C)$ 5-d-old MDM that have not been treated with exogenous iron, $\times 5,400$. Iron was localized as small aggregates throughout the cytosol (arrows) of the chronically iron-overloaded MDM $(A)$ but was not detectable in the other two cell populations $(B$ and $C)$.

other tissue macrophages. The work also further demonstrates the importance of intracellular iron sequestration as a means of preventing macrophage-associated iron from catalyzing extracellular $\cdot \mathrm{OH}$ generation. Using a system similar to that recently reported (61), MDM could be acutely iron overloaded

\section{Mn SOD}

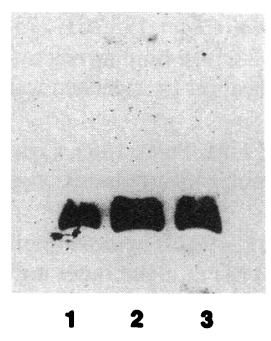

Catalase

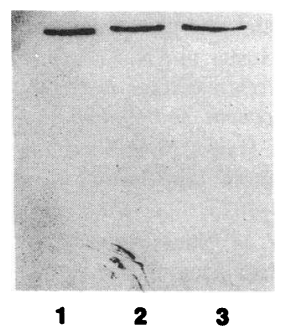

CuZn SOD

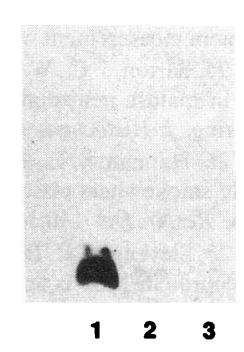

Figure 6. Effect of iron loading on antioxidant enzyme levels of MDM. Representative immunoblots of antioxidant enzymes from untreated control and chronically iron-loaded MDM. Shown are results with $(A) \mathrm{MnSOD},(B) \mathrm{CuZnSOD}$, and $(C)$ catalase. In each panel lane 1 contains purified human antigen, lane 2 contains untreated MDM, and lane 3 contains chronically iron-loaded MDM. No difference in the amount of immunoreactive MnSOD, CuZnSOD, or catalase was detectable between the two cell types. in such a way as to yield cells whose iron content was similar to AM from smokers. In contrast to AM from smokers, however, stimulation of acutely iron-loaded MDM generated extracellular $\cdot \mathrm{OH}$. Results with Fe-citrate-loaded cells were less dramatic than when FeNTA or FeADP were used, likely related to the lesser uptake of iron bound to citrate. The reason for the detection of apparent $\cdot \mathrm{OH}$ formation after PMA stimulation of Fe-citrate-loaded cells by the deoxyribose assay but not any of the spin trapping techniques is not clear. The deoxyribose assay may be more sensitive for $\cdot \mathrm{OH}$ under the conditions employed or, alternatively, could be detecting the production of an oxidant species other than $\cdot \mathrm{OH}$, such as a ferryl species (64), which may not be detectable with the spin trapping methods employed.

Consistent with results in another cell system (65), most of the cell-associated iron after exposure to FeNTA, FeADP, and Fe-citrate appeared initially to be localized to the plasma membrane. Movement of iron from the membrane to intracellular sites was associated with a progressive decrease in the magnitude of $\cdot \mathrm{OH}$ generation along with an increase in ferritin. It seems likely that the ability of acutely iron-loaded macrophages to generate $\cdot \mathrm{OH}$ upon stimulation reflects the presence of catalytic iron at the same site (plasma membrane) as the ongoing generation of $\cdot \mathrm{O}_{2}^{-} / \mathrm{H}_{2} \mathrm{O}_{2}$ by the phagocyte NADPHdependent oxidase. Loss of $\cdot \mathrm{OH}$-generating capacity over time 
likely results from the transfer of this iron to intracellular ferritin and hemosiderin. Alterations in the cellular antioxidant enzymes or induction of heat-shock protein (HSP-70) do not appear to be involved. However, it remains possible that other heat-shock proteins or additional proteins reported to protect cells from iron-associated oxidative stress $(66,67)$ could be involved.

The mechanism whereby MDM can transport small molecular weight iron chelates such as FeNTA is unclear. Most studies of iron transport in macrophages have concentrated on the uptake of iron bound to transferrin $(68,69)$. Previous work has shown that peripheral blood monocytes take up iron bound to NTA with a corresponding increase in ferritin content (70). These results contrast somewhat studies performed with rabbit reticulocytes where hemin but not other iron complexes induce ferritin synthesis $(71,72)$. Consistent with studies of other cells $(65,73-75)$, preliminary data from our own laboratory suggest that MDM take up iron much more rapidly when it is bound to low molecular weight chelates compared with transferrin and that the mechanism resembles in some ways fluid phase pinocytosis (76). Smoking itself may alter macrophage iron transport so as to increase iron storage (77).

In summary, human macrophages have the capacity to transfer large quantities of extracellular iron to intracellular locations over time. This storage process decreases the potential for this iron to induce the generation of extracellular $\cdot \mathrm{OH}$ and may be an important means of protecting nearby cells from exposure to potentially cytotoxic $\cdot \mathrm{OH}$. A similar hypothesis has recently been put forward with regard to endothelial cells (59). Additional studies are required to clarify the mechanism of the intracellular sequestration of low molecular weight iron chelates by human macrophages and the role of this process in limiting inflammatory tissue injury.

\section{Acknowledgments}

We thank Brian Edeker, Danielle Hamill, Diane Lilleg, Michelle Railsback, and Dr. Thomas Coffman for technical assistance; Tom Moninger (University of Iowa Electron Microscopy Facility) for obtaining the electron micrographs; the Special Chemistry Laboratory of the University of Iowa Hospitals and Clinics for performing the ferritin assay; and Naomi Erickson for preparation of the manuscript.

This work was supported in part by the Veterans Administration Research Service (BEB and SEM); Public Health Service Grants HL 44275 (B. E. Britigan), AI 28412 (B. E. Britigan), and HL 39328 (S. E. McGowan); the Pfizer Scholars Program (B. E. Britigan), and a GrantIn-Aid from the American Heart Association. It was performed during the tenure of Veterans Administration Research Associate Career Awards to Drs. Britigan and McGowan.

This work was presented in part at the Interscience Conference on Antimicrobial Agents and Chemotherapy, October 24, 1988 in Los Angeles, CA and the annual meeting of the American Association of Immunologists, June 4, 1990 in New Orleans, LA.

\section{References}

1. Janoff, A., H. Carp, P. Laurent, and L. Raju. 1983. The role of oxidative processes in emphysema. Am. Rev. Respir. Dis. 127:S31-S38.

2. Niewoehner, D. E., J. Kleinerman, and D. B. Rice. 1974. Pathologic changes in the peripheral airways of young cigarette smokers. N. Engl. J. Med. 291:755-758.

3. Davis, W. B., E. R. Pacht, M. Spatafora, and W. J. Martin II. 1988. Enhanced cytotoxic potential of alveolar macrophages from cigarette smokers. $J$. Lab. Clin. Med. 111:293-298.

4. Baughman, R. P., B. C. Corser, S. Strohofer, and D. Hendricks. 1986.
Spontaneous hydrogen peroxide release from alveolar macrophages of some cigarette smokers. J. Lab. Clin. Med. 107:233-237.

5. Greening, A. P., and D. B. Lowrie. 1983. Extracellular release of hydrogen peroxide by human alveolar macrophages: the relationship to cigarette smoking and lower respiratory tract infections. Clin. Sci. 65:661-664.

6. Hoidal, J. R., R. B. Fox, P. A. LeMarbe, R. Perri, and J. E. Repine. 1981. Altered oxidative metabolic responses in vitro of alveolar macrophages from asymptomatic cigarette smokers. Am. Rev. Respir. Dis. 123:85-89.

7. McGowan, S. E., J. J. Murray, and M. G. Parrish. 1986. Iron binding, internalization, and fate in human alveolar macrophages. J. Lab. Clin. Med. 108:587-595

8. McGowan, S. E., and S. A. Henley. 1988. Iron and ferritin content and distribution in human alveolar macrophages. J. Lab. Clin. Med. 111:611-617.

9. Thompson, A. B., T. Bohling, A. Heires, J. Linder, and S. I. Rennard. 1991. Lower respiratory tract iron burden is increased in association with cigarette smoking. J. Lab. Clin. Med. 117:493-499.

10. Jacobs, A. 1977. Iron overload-clinical and pathologic aspects. Semin. Hematol. 14:89-113.

11. Ballart, I. J., M. E. Estevez, L. Sen, R. A. Diez, J. Giuntoli, S. A. de Miani, and J. Penalver. 1986. Progressive dysfunction of monocytes associated with iron overload and age in patients with thalassemia major. Blood. 67:105-109.

12. Janoff, A., W. A. Pryor, and Z. H. Bengali. 1987. Effects of tobacco smoke components on cellular and biochemical processes in the lung. Am. Rev. Respir. Dis. 136:1058-1064.

13. Weiss, S. J. 1986. Oxygen, ischemia and inflammation. Acta Physiol Scand. Suppl. 548:9-37.

14. Nakagawara, A., C. F. Nathan, and Z. A. Cohn. 1981. Hydrogen peroxide metabolism in human monocytes during differentiation in vitro. J. Clin. Invest. 68:1243-1252.

15. Haber, F., and J. Weiss. 1934. The catalytic decomposition of hydrogen peroxide by iron salts. Proc. R. Soc. Lond. Math. Phys. Soc. 147:332-351.

16. Britigan, B. E., T. J. Coffman, D. R. Adelberg, and M. S. Cohen. 1988. Mononuclear phagocytes have the potential for sustained hydroxyl radical production: use of spin trapping techniques to investigate mononuclear phagocyte free radical production. J. Exp. Med. 168:2367-2372.

17. Greenwald, R. A., S. W. Rush, S. A. Mark, and Z. Weitz. 1989. Conversion of superoxide generated by polymorphonuclear leukocytes to hydroxyl radical: a direct spectrophotometric detection system based on degradation of deoxyribose. Free Radical Biol. Med. 6:385-392.

18. Halliwell, B., and J. M. C. Gutteridge. 1981. Formation of a thiobarbituric acid-reactive substance from deoxyribose in the presence of iron salts. The role of superoxide and hydroxyl radicals. FEBS (Fed. Eur. Biochem. Soc.) Lett. 128:347-351.

19. Halliwell, B., J. M. C. Gutteridge, and O. I. Aruoma. 1987. The deoxyribose method: a simple "test-tube" assay for determination of rate constants for reactions of hydroxyl radicals. Anal. Biochem. 165:215-219.

20. Britigan, B. E., T. J. Coffman, and G. R. Buettner. 1990. Spin trap evidence for the lack of significant hydroxyl radical production during the respiration burst of human phagocytes using a spin adduct resistant to superoxide mediated destruction. J. Biol. Chem. 265:2650-2656.

21. Bynoe, L. A., S. Pou, J. D. Gottsch, and G. M. Rosen. 1991. Light-dependent spin trapping of hydroxyl radical from human erythrocytes. Biochem. Biophys. Res. Commun. 179:1305-1310.

22. Ramos, C. L., S. Pou, B. E. Britigan, M. S. Cohen, and G. M. Rosen. 1992. Spin trapping evidence for myeloperoxidase-dependent hydroxyl radical formation by human neutrophils and monocytes. J. Biol. Chem. 267:8307-8312.

23. Hassan, H. M., and I. Fridovich. 1980. Mechanism of the antibiotic action of pyocyanine. J. Bacteriol. 141:156-163.

24. Lowry, O. H., N. F. Rosebrough, A. G. Far, and R. J. Randall. 1951. Protein measurement with the folin phenol reagent. J. Biol. Chem. 193:265-275.

25. Barton, J. C., W. J. Huster, and R. T. Parmley. 1988. Iron-binding reactivity in mature neutrophils: relative cell content quantification by cytochemical scoring. J. Histochem. Cytochem. 36:649-658.

26. Hannan, S. E., J. O. Harris, N. P. Sheridan, and J. M. Patel. 1989. Cigarette smoke alters plasma membrane fluidity of rat alveolar macrophages. $\mathrm{Am}$ Rev. Respir. Dis. 140:1668-1673.

27. Stevenson, K. B., W. M. Nauseef, and R. A. Clark. 1987. The neutrophil glycoprotein $\mathrm{Mol}$ is an integral membrane protein of plasma membranes and specific granules. J. Immunol. 139:3759-3763.

28. Wannemuehler, Y., K. Johansen, and R. Rosenbusch. 1989. Identification of Moraxella bovis by using a monoclonal antibody to lipopolysaccharide epitope. J. Clin. Microbiol. 27:2881-2883.

29. Oberley, L. W., D. Kasemset-St. Clair, A. Autor, and T. D. Oberley. 1987. Increase in manganese superoxide dismutase activity in the mouse heart after X-irradiation. Arch. Biochem. Biophys. 254:69-80.

30. Ogata, K. 1988. Immunovisualization with peroxidase-labeled anti-bodies, the peroxidase antiperoxidase, and biotin-streptavidin methods. In CRC Handbook of Immunoblotting of Proteins, Vol. 1 Technical Descriptions. O. J. Bjerrum and N. H. H. Heegaard, editors. CRC Press, Boca Raton, FL. 167-176. 
31. Rosen, G. M., and E. Finkelstein. 1985. Use of spin traps in biological systems. Adv. Free Radical Biol. Med. 1:345-375.

32. Pou, S., D. J. Hassett, B. E. Britigan, M. S. Cohen, and G. M. Rosen. 1989 Problems associated with spin trapping oxygen-centered free radicals in biological systems. Anal. Biochem. 177:1-6.

33. Cosgrove, J. P., E. T. Borish, D. F. Church, and W. A. Pryor. 1985. The metal-mediated formation of hydroxyl radical by aqueous extracts from cigarette tar. Biochem. Biophys. Res. Commun. 132:390-396.

34. Qian, M., and J. W. Eaton. 1989. Tobacco-borne siderophoric activity. Arch. Biochem. Biophys. 275:280-288.

35. Howell, D. R., B. E. Britigan, R. B. Fick, Jr., and C. D. Cox. 1990. Levels of iron and iron-binding proteins in bronchoalveolar lavage fluids of cystic fibrosis subjects. Clin. Res. 38:274a. (Abstr.)

36. Thompson, A. B., T. Bohling, F. Payvandi, and S. I. Rennard. 1990. Lower respiratory tract lactoferrin and lysozyme arise primarily in the airways and are elevated in association with chronic bronchitis. J. Lab. Clin. Med. 115:148-158.

37. Craig, E. A. 1985. The heat shock response. CRC Crit. Rev. Biochem. 18:239-280.

38. Mussalo-Rauhammaa, H., S. S. Salmella, A. Leppanen, and H. Pyysalo. 1986. Cigarettes as a source of some trace and heavy metals and pesticides in man. Arch. Environ. Health. 41:49-55.

39. Sutton, H. C. 1985. Efficiency of chelated iron compounds as catalysts for the Haber-Weiss reaction. J. Free Radical Biol. Med. 1:195-202.

40. Ward, P. A., G. O. Till, R. Kunkel, and C. Beauchamp. 1983. Evidence for the role of hydroxyl radical in complement and neutrophil-dependent tissue injury. J. Clin. Invest. 72:789-801.

41. Fox, R. B. 1984. Prevention of granulocyte mediated lung injury in rats by a hydroxyl radical scavenger, dimethylthiourea. J. Clin. Invest. 74:1456-1464.

42. Till, G. O., J. R. Hatherill, W. W. Tourtellotte, M. J. Lutz, and P. A. Ward. 1985. Lipid peroxidation and acute lung injury after thermal trauma to skin. $\mathrm{Am}$. J. Pathol. 119:376-384.

43. Gannon, D. E., J. Varani, S. H. Phan, J. H. Ward, J. Kaplan, G. O. Till, R. H. Simon, U. S. Ryan, and P. A. Ward. 1987. Source of iron in neutrophil-mediated killing of endothelial cells. Lab. Invest. 57:37-44.

44. Kuroda, M., K. Murakami, and Y. Ishikawa. 1987. Role of hydroxyl radicals derived from granulocytes in lung injury induced by phorbol myristate acetate. Am. Rev. Respir. Dis. 135:1435-1444.

45. Weiss, S. J., G. W. King, and A. F. LoBuglio. 1977. Evidence for hydroxyl radical generation by human monocytes. J. Clin. Invest. 60:370-373.

46. Speer, C. P., D. R. Ambruso, J. Grimsley, and R. B. Johnston, Jr. 1985. Oxidative metabolism in cord blood monocytes and monocyte-derived macrophages. Infect. Immun. 50:919-921.

47. Hume, D. A., S. Gordon, P. J. Thornalley, and J. V. Bannister. 1983. The production of oxygen-centered radicals by Bacillus-Calmette-Guerin-activated macrophages: an electron paramagnetic resonance study of the response to phorbol myristate acetate. Biochim. Biophys. Acta. 763:245-250.

48. Hoidal, J. R., G. D. Beall, and J. E. Repine. 1979. Production of hydroxyl radical by human alveolar macrophages. Infect. Immun. 26:1088-1092.

49. Ito, M., R. Karmali, and M. Krim. 1985. Effect of interferon on chemiluminescence and hydroxyl radical production in murine macrophages stimulated by PMA. Immunology. 56:533-541.

50. Karnovsky, M. L., and J. A. Badwey. 1983. Determinants of the production of active oxygen species by granulocytes and macrophages. J. Clin. Chem Clin. Biochem. 21:545-553

51. Janco, R. L., and D. English. 1983. Regulation of monocyte oxidative metabolism: chemotactic factor enhancement of superoxide release, hydroxyl radical generation, and chemiluminescence. J. Lab. Clin. Med. 102:890-898.

52. Niwa, Y., T. Sakane, Y. Miyachi, and M. Ozaki. 1984. Oxygen metabolism in phagocytes of leprotic patients: enhanced endogenous superoxide dismutase activity and hydroxyl radical generation by clofazamine. J. Clin. Microbiol. 20:837-842.

53. Cohen, M. S., B. E. Britigan, D. J. Hassett, and G. M. Rosen. 1988. Do human neutrophils form hydroxyl radical? Evaluation of an unresolved controversy. Free Radical Biol. Med. 5:81-88.

54. Buettner, G. R. 1988. In the absence of catalytic metals ascorbate does not autoxidize at $\mathrm{pH}$ 7: ascorbate as a test for catalytic metals. J. Biochem. Biophys. Methods. 16:27-40.

55. Wesselius, L. J., C. H. Flowers, and B. S. Skikne. 1992. Alveolar macrophage content of isoferritins and transferrin: comparison of nonsmokers and smokers with and without chronic airflow obstruction. Am. Rev. Respir. Dis. 145:311-316.
56. O'Connell, M., B. Halliwell, C. P. Moorhouse, O. I. Aruoma, H. Baum, and T. J. Peters. 1986. Formation of hydroxyl radicals in the presence of ferritin and haemosiderin. Is haemosiderin formation a biological protective mechanism? Biochem. J. 234:727-731.

57. Ozaki, M., T. Kawabata, and M. Awai. 1988. Iron release from haemosiderin and production of iron-catalyzed hydroxyl radicals in vitro. Biochem. $J$ 250:589-595.

58. Cozzi, A., P. Santambrogio, S. Levi, and P. Arosio. 1990. Iron detoxifying activity of ferritin: effects of $\mathrm{H}$ and $\mathrm{L}$ human apoferritins on lipid peroxidation in vitro. FEBS (Fed. Eur. Biochem. Soc.) Lett. 277:119-122.

59. Balla, G., H. S. Jacob, J. Balla, M. Rosenberg, K. Nath, F. Apple, J. W. Eaton, and G. M. Vercellotti. 1992. Ferritin: a cytoprotective antioxidant strategem of endothelium. J. Biol. Chem. 267:18148-18153.

60. Byrd, T. F., and M. A. Horwitz. 1989. Interferon gamma-activated human monocytes downregulate transferrin receptors and inhibit the intracellular multiplication of Legionella pneumophila by limiting the availability of iron. J. Clin. Invest. 83:1457-1465.

61. Byrd, T. F., and M. A. Horwitz. 1991. Lactoferrin inhibits or promotes Legionella pneumophila intracellular multiplication in nonactivated and interferon gamma-activated human monocytes depending upon its degree of iron saturation. Iron-lactoferrin and nonphysiologic iron chelates reverse monocyte activation against Legionella pneumophila. J. Clin. Invest. 88:1103-1112.

62. Alford, C. E., T. E. King, Jr., and P. A. Campbell. 1991. Role of transferrin, transferrin receptors, and iron in macrophage listericidal activity. J. Exp. Med. 174:459-466.

63. Kitamure, S. 1987. Effects of cigarette smoking on metabolic events in the lung. Environ. Health Perspect. 72:283-296.

64. Winterbourn, C. C. 1987 . The ability of scavengers to distinguish $\cdot \mathrm{OH}$ production in the iron catalyzed Haber-Weiss reaction. Comparison of four assays for - OH. Free Radical Biol. Med. 3:33-39.

65. White, G. P., and A. Jacobs. 1978. Iron uptake by Chang cells from transferrin, nitriloacetate and citrate complexes: the effects of iron-loading and chelation with desferrioxamine. Biochim. Biophys. Acta. 543:217-225.

66. Keyse, S. M., and R. M. Tyrrell. 1989. Heme oxygenase is the major 32-kDa stress protein induced in human skin fibroblasts by UVA radiation, hydrogen peroxide, and sodium arsenite. Proc. Natl. Acad. Sci. USA. 86:99-103.

67. Stocker, R. 1990. Induction of haem oxygenase as a defence against oxidative stress. Free Radical Biol. Med. 9:101-112.

68. De Jong, G., J. P. Van Dijk, and H. G. Van Eijk. 1990. The biology of transferrin. Clin. Chim. Acta. 190:1-46.

69. Thorstensen, K., and I. Romslo. 1990. The role of transferrin in the mechanism of cellular iron uptake. Biochem. J. 271:1-10.

70. Worwood, M., D. Hourahane, and B. M. Jones. 1984. Accumulation and release of isoferritins during incubation in vitro of human peripheral blood mononuclear cells. Br. J. Haematol. 56:31-43.

71. Lin, J.-J., S. Daniels-McQueen, M. M. Patino, L. Gaffield, W. E. Walden, and R. E. Thach. 1990. Derepression of ferritin messenger RNA translation by hemin in vitro. Science (Wash. DC). 247:74-77.

72. Lin, J. J., S. Daniels-McQueen, L. Gaffield, M. M. Patino, W. E. Walden, and R. E. Thach. 1990. Specificity of the induction of ferritin synthesis by hemin. Biochim. Biophys. Acta. 1050:146-150.

73. Sturrock, A., J. Alexander, J. Lamb, C. M. Craven, and J. Kaplan. 1990. Characterization of a transferrin-independent uptake system for iron in HeLa cells. J. Biol. Chem. 265:3139-3145.

74. Kaplan, J., I. Jordan, and A. Sturrock. 1991. Regulation of the transferrinindependent iron transport system in cultured cells. J. Biol. Chem. 266:29973004.

75. Richardson, D., and E. Baker. 1991. The uptake of inorganic iron complexes by human melanoma cells. Biochim. Biophys. Acta 1093:20-28.

76. Olakanmi, O., and B. E. Britigan. 1992. Mechanisms of uptake of small molecular weight iron chelates by human monocyte-derived macrophages. $F A$ SEB (Fed. Am. Soc. Exp. Biol.) J. 6:A 1486. (Abstr.)

77. Valberg, P. A., W. A. Jensen, and R. M. Rose. 1990. Cell organelle motions in bronchoalveolar lavage macrophages from smokers and nonsmokers. Am. Rev. Respir. Dis. 141:1272-1279.

78. Britigan, B. E., S. Pou, G. M. Rosen, D. M. Lilleg, and G. R. Buettner 1990. Hydroxyl radical is not a product of the reaction of xanthine oxidase and xanthine. The confounding problem of adventitious iron bound to xanthine oxidase. J. Biol. Chem. 265:17533-17538.

79. Diguiseppi, J., and I. Fridovich. 1980. Ethylene from 2-keto-4-thiomethyl butyric acid: the Haber-Weiss reaction. Arch. Biochem. Biophys. 295:323-329. 